\title{
PATTERN OF PSYCHIATRIC MORBIDITY AMONG REFERRED PATIENTS TO THE DEPARTMENT OF PSYCHIATRY IN SUPER SPECIALITY HOSPITAL OF KASHMIR
}

\author{
Ab. Majid Gania1 , Ajaz Ahmad Suhaff2, Bilal Ahmad Hakak³, A. W. Khan', Junaid Nabi5, Asma Manzoor6 \\ ${ }_{1}^{1}$ Assistant Professor, Department of Psychiatry, SKIMS Medical College/Hospital, Bemina, Srinagar, J \& K. \\ ${ }^{2}$ Resident, Department of Psychiatry, SKIMS Medical College/Hospital, Bemina, Srinagar, J \& K. \\ ${ }^{3}$ Senior Resident, Department of Psychiatry, SKIMS Medical College/Hospital, Bemina, Srinagar, J \& K. \\ ${ }^{4}$ Professor, Department of Psychiatry, SKIMS Medical College/Hospital, Bemina, Srinagar, J \& K. \\ 5 Senior Resident, Department of Psychiatry, SKIMS Medical College/Hospital, Bemina, Srinagar, J \& K. \\ ${ }^{6}$ Senior Resident, Department of Psychiatry, SKIMS Medical College/Hospital, Bemina, Srinagar, J \& K.
}

\begin{abstract}
BACKGROUND
ABSTRACT

The paper discusses the role of referrals in psychiatric practice using referrals from various departments in super-speciality teaching hospital. It is a care delivered by psychiatrists to patients with co-occurring medical and psychiatric problems who are being treated primarily in medical settings. The department of psychiatry in a super-speciality hospital setting, has a multidimensional role providing inpatient care, maintaining strong interaction with community psychiatric services and offering specialist services to the general hospital wards either as part of the multidisciplinary approach to patient management or by offering specialist inpatient care to patients already hospitalised in other departments, or attending patients referred from other departments with psychiatric problems. ${ }^{1-3}$ The most referrals were from department of medicine with most common reasons being depression, anxiety and somatic symptoms.
\end{abstract}

\section{MATERIALS AND METHODS}

This cross-sectional study was conducted at Sher-e-Kashmir Institute of Medical Sciences (SKIMS). All patients being referred to psychiatry were included in the study over 3-month period. The information was recorded on a structured questionnaire and analysed the data using SPSS. A total of 350 patients were referred to psychiatry from various departments.

\section{RESULTS}

Average age of the patients referred to was 32.6 years. 151 (48.2\%) referrals were males. $71(22.7 \%)$ referrals were from Cardiology, 46 (14.7\%) from Neurology, 39 (12.5\%) from General Medicine, 36 (11.5\%) from Gastroenterology, 28(8\%) from Physical Medicine, 24 (7.7\%) from Accident \& Emergency, 22 (7\%) from Endocrinology, and 47 (15\%) were from various other departments. Among the various reasons of referrals, 40 (12.8\%) were for depressive disorder, 29 (9.3\%) for functional neurological symptom disorder, 28 (8.9\%) for generalised anxiety disorder, 27 (8.6\%) for panic disorder and somatic symptom disorder each. 162 (51.8\%) referrals for other reasons.

\section{CONCLUSION}

We concluded that awareness of using referral services is most important. We also conclude that it was necessary for a physician to have a comprehensive knowledge of psychiatric symptoms and timely intervention should be adopted in referral system.

\section{KEYWORDS}

Referrals, Psychiatry, Tertiary Care Hospital.

HOW TO CITE THIS ARTICLE: Gania AM, Suhaff AA, Hakak BA, et al. Pattern of psychiatric morbidity among referred patients to the department of psychiatry in super-speciality hospital of Kashmir. J. Evolution Med. Dent. Sci. 2016;5(77):5695-5700, DOI: $10.14260 /$ jemds/2016/1285

INTRODUCTION
Psychiatric diseases are on the rise with an alarming $7.4 \%$ of
the global burden of disease being attributed to them. In
developing countries, an estimated $75 \%$ people battling
mental health disorders do not receive any kind of
treatment. ${ }^{4}$ Establishment of psychiatric units in general
hospitals have provided opportunities for interaction
between psychiatrist and other medical specialities.

Financial or Other, Competing Interest: None.

Submission 17-08-2016, Peer Review 12-09-2016,

Acceptance 19-09-2016, Published 24-09-2016.

Corresponding Author:

Dr. Ab. Majid Gania,

Department of Psychiatry,

SKIMS Medical College/ Hospital,

Bemina, Srinagar, J \& K, India.

E-mail: maajid72@gmail.com

DOI: $10.14260 /$ jemds $/ 2016 / 1285$
Similarly, the rate of psychiatric morbidity in medical inpatients is also continuously reported high in different studies in different countries. ${ }^{6}$ Moreover high prevalence of psychiatric illness is reported among general hospital OPD patients. 7,8

Psychiatric service of a general hospital has extra advantages of easier access, less stigma and visible acceptance to medical field. ${ }^{9}$ Psychiatry has become an essential part of general hospital settings, providing in and outpatients services, providing specialist input to patients admitted to other departments in general hospital. Because the flow of patients with psychiatric comorbidity admitted to general hospital is huge. DSM criterion for psychiatric diagnosis of patients admitting in non-psychiatric wards is about $27 \% .^{10}$ In Kashmir, with the advent of growing threat of terrorism and mass unarmed uprising, economical decline and unemployment among other factors, neuropsychiatric disorders have reached new heights. It has been observed 
that psychiatric conditions are independent risk factor for diseases like myocardial Infarction and diabetes mellitus, but also plays a vital role in the prognosis of these illnesses. Therefore, significant number of patients require specialist psychiatric opinion. 11

Moreover, hospital stay has been shown to be prolonged with concurrent psychiatric comorbidity. This further leads to increased hospital costs and burden on resources. Psychiatric disorders which are more prevalent in patients with chronic illnesses compared to general population are anxiety, affective and substance abuse disorders. ${ }^{12}$

In general hospital setting, department of psychiatry has to play a vital role by providing in-patient care, maintaining strong interaction with community psychiatric services and offering specialist services to the general hospital wards..$^{1,2}$

\section{MATERIALS AND METHODS}

The study was carried out to observe the distribution of the referrals to the Department of Psychiatry from various departments to observe the variability of referrals in terms of age and sex, to evaluate the pattern of psychiatric referrals and to study various diagnostic categories associated with physical disorders. All patients referred to psychiatric outpatient department from various specialist departments of SKIMS hospital, willing to participate were included in the study, while those not willing to participate or referrals from other hospitals were excluded. The study was conducted in Sher-e-Kashmir Institute of Medical Sciences (SKIMS), Srinagar, a super-speciality teaching hospital, which has total of 850-bed capacity with almost all specialty departments and offers outpatient and inpatient health services to patients referred from all over the state of Jammu \& Kashmir. This study included all the patients referred to department of psychiatry during the period of 3 months. All other patients attending psychiatric services at psychiatry outpatient department (OPD), and psychiatry indoor patients (IPD) were excluded. The study protocol was approved by the Institutional Ethics Committee.

Special proforma was prepared for the study which included Social-demographic profile, Clinical profile (including history of Present complaints Medical and Psychiatric, Clinical examination and Diagnosis) source of referral, and comorbid conditions. Out of 350 patients referred to psychiatric department during the study period, $37(10.57 \%)$ were excluded from the study as they didn't fulfil the inclusion criteria for DSM diagnosis. Thus, only 313 patients satisfying were enrolled in the study. After written informed consent, each patient was individually interviewed along the special proforma prepared for the study. MINI International Neuropsychiatric interview plus was administered for diagnosing Psychiatric disorders.

MINI international Neuropsychiatric Interview Plus (MINI-Plus) is a comprehensive diagnostic semi-structured interview that has been widely used. The MINI-Plus possesses good inter-ratter reliability. The MINI-Plus possesses very good test-retest reliability for the diagnoses of drug and alcohol abuse and dependence. It is based on DSM IV and ICD 10.13 All data thus collected was tabulated and analysed statistically using Statistical Package for Social Science' (SPSS) - software under guidance of a statistician and conclusions were drawn.
RESULTS AND OBSERVATIONS

\begin{tabular}{|c|c|c|c|}
\hline \multicolumn{4}{|c|}{ Age Distribution of Referral Patients } \\
\hline Age (Years) & No. & $\begin{array}{c}\text { Percentage } \\
\text { (\% Age) }\end{array}$ & $\begin{array}{c}\text { Mean } \pm \text { SD } \\
\text { [Range] }\end{array}$ \\
\hline $0-11$ & 16 & 5.1 & \multirow{6}{*}{$\begin{array}{c}32.6 \pm 16.42 \\
{[4-80]}\end{array}$} \\
\hline $12-19$ & 67 & 21.4 & \\
\hline $20-39$ & 123 & 39.3 & \\
\hline $40-59$ & 89 & 28.4 & \\
\hline$\geq 60$ & 18 & 5.8 & \\
\hline Total & 313 & 100 & \\
\hline \multicolumn{4}{|c|}{ Table 1} \\
\hline
\end{tabular}

\begin{tabular}{|c|c|c|c|}
\hline \multicolumn{4}{|c|}{$\begin{array}{l}\text { Socio-demographic Characteristics of } \\
\text { Referral Patients }\end{array}$} \\
\hline \multicolumn{2}{|c|}{ Characteristic } & No. & $\begin{array}{l}\text { Percentage } \\
\text { (\% Age) }\end{array}$ \\
\hline \multirow{2}{*}{ Gender } & Male & 151 & 48.2 \\
\hline & Female & 162 & 51.8 \\
\hline \multirow{2}{*}{ Residence } & Rural & 182 & 58.1 \\
\hline & Urban & 131 & 41.9 \\
\hline \multirow{7}{*}{$\begin{array}{l}\text { Educational } \\
\text { Status }\end{array}$} & Illiterate & 130 & 41.5 \\
\hline & Primary & 11 & 3.5 \\
\hline & Middle & 5 & 1.6 \\
\hline & High School & 108 & 34.5 \\
\hline & $\begin{array}{c}\text { Higher } \\
\text { Secondary }\end{array}$ & 3 & 1.0 \\
\hline & Graduate & 51 & 16.3 \\
\hline & Post Graduate & 5 & 1.6 \\
\hline \multirow{3}{*}{ Occupation } & Student & 62 & 19.8 \\
\hline & Unemployed & 134 & 42.8 \\
\hline & Employed & 117 & 37.4 \\
\hline \multirow{4}{*}{ Marital Status } & Unmarried & 154 & 49.2 \\
\hline & Married & 139 & 44.4 \\
\hline & Widow & 12 & 3.8 \\
\hline & Divorce & 8 & 2.6 \\
\hline \multirow{3}{*}{$\begin{array}{c}\text { Socio-economic } \\
\text { Status }\end{array}$} & Lower Class & 86 & 27.5 \\
\hline & Middle Class & 187 & 59.7 \\
\hline & Upper Class & 40 & 12.8 \\
\hline \multicolumn{4}{|c|}{ Table 2} \\
\hline
\end{tabular}

Mean age of the patients referred to psychiatric department was 32.6 years \pm SD 16.42. Out of total 313 referrals during our studied period, 151 (48.2\%) referrals were males and 162 (51.8\%) were females. 182 (58.1\%) belonged to rural areas and 131 (41.9\%) were from urban background, 139 (44.4\%) were married, 183 (58.5\%) were educated and majority of the patients 187 (59.7\%) were from middle socio-economic class.

\begin{tabular}{|c|c|c|c|c|}
\hline \multirow{2}{*}{$\begin{array}{c}\text { Distribution by Specialities among Referrals } \\
\text { Rpecialities }\end{array}$} & \multicolumn{2}{|c|}{ Gender } & \multicolumn{2}{c|}{$\begin{array}{c}\text { Total no. of } \\
\text { Referrals }\end{array}$} \\
\cline { 2 - 5 } & Male & Female & No. & $\%$ \\
\hline Accident/Emergency & 7 & 17 & 24 & 7.7 \\
\hline Cardiology & 40 & 31 & 71 & 22.7 \\
\hline Endocrinology & 14 & 8 & 22 & 7.0 \\
\hline Gastroenterology & 18 & 18 & 36 & 11.5 \\
\hline General Medicine & 23 & 16 & 39 & 12.5 \\
\hline Nephrology & 3 & 3 & 6 & 1.9 \\
\hline Neurology & 23 & 23 & 46 & 14.7 \\
\hline Oncology & 9 & 8 & 17 & 5.4 \\
\hline
\end{tabular}




\begin{tabular}{|c|c|c|c|c|}
\hline Paediatrics & 10 & 6 & 16 & 5.1 \\
\hline Plastic Surgery & 3 & 5 & 8 & 2.6 \\
\hline PMR & 12 & 16 & 28 & 8.9 \\
\hline Total & $\mathbf{1 6 2}$ & $\mathbf{1 5 1}$ & $\mathbf{3 1 3}$ & $\mathbf{1 0 0}$ \\
\hline \multicolumn{5}{|c|}{ Table 3 } \\
\hline
\end{tabular}

Referrals were mostly from Cardiology and Neurology. 71 (22.7\%) from Cardiology, 46 (14.7\%) from Neurology, 39 (12.5\%) from General Medicine, 36 (11.5 \%) from Gastroenterology, 28 (8.9\%) from Physical Medicine and Rehabilitation, 24 (7.7\%) from Accident and Emergency, 22 (7.0\%) from Endocrinology, 17 (5.4\%) from Oncology, 16 (5.1\%) from Paediatrics, 8 (2.6\%) from Plastic Surgery and 6 (1.9\%) from Nephrology.

\begin{tabular}{|c|c|c|c|c|}
\hline \multicolumn{5}{|c|}{ Psychiatric Diagnosis in Referral Patients } \\
\hline \multirow{2}{*}{$\begin{array}{l}\text { Psychiatric } \\
\text { Diagnosis }\end{array}$} & \multicolumn{2}{|c|}{ Gender } & \multicolumn{2}{|c|}{$\begin{array}{c}\text { Total no. of } \\
\text { Referrals }\end{array}$} \\
\hline & Male & Female & No. & $\%$ \\
\hline Acute Stress Reaction & 1 & 3 & 4 & 1.3 \\
\hline ADHD & 1 & 3 & 4 & 1.3 \\
\hline $\begin{array}{l}\text { Anxiety Disorder Due } \\
\text { To Another Medical } \\
\text { Condition }\end{array}$ & 3 & 3 & 6 & 1.9 \\
\hline $\begin{array}{c}\text { Autistic Spectrum } \\
\text { Disorders (ASD) }\end{array}$ & 3 & 2 & 5 & 1.6 \\
\hline $\begin{array}{l}\text { Bipolar Affective } \\
\text { Disorder }\end{array}$ & 7 & 0 & 7 & 2.2 \\
\hline BPSD & 1 & 1 & 2 & 0.6 \\
\hline Brief Psychotic Disorder & 5 & 1 & 6 & 1.9 \\
\hline $\begin{array}{l}\text { Chronic Fatigue } \\
\text { Syndrome }\end{array}$ & 1 & 1 & 2 & 0.6 \\
\hline Conduct Disorder & 1 & 0 & 1 & 0.3 \\
\hline Delusional Disorder & 1 & 3 & 4 & 1.3 \\
\hline Depressive Disorder & 19 & 21 & 40 & 12.8 \\
\hline Dissociative Disorder & 2 & 11 & 13 & 4.2 \\
\hline Eating Disorder & 0 & 4 & 4 & 1.3 \\
\hline Elimination Disorder & 2 & 1 & 3 & 1.0 \\
\hline $\begin{array}{l}\text { Functional Neurological } \\
\text { Symptom Disorder }\end{array}$ & 13 & 16 & 29 & 9.3 \\
\hline $\begin{array}{c}\text { Generalised Anxiety } \\
\text { disorder }\end{array}$ & 19 & 9 & 28 & 8.9 \\
\hline Illness Anxiety Disorder & 8 & 12 & 20 & 6.4 \\
\hline Intellectual Disability & 3 & 0 & 3 & 1.0 \\
\hline $\begin{array}{l}\text { Irritable Bowel } \\
\text { Syndrome }\end{array}$ & 1 & 0 & 1 & 0.3 \\
\hline Tic Disorder & 1 & 0 & 1 & 0.3 \\
\hline OCD & 3 & 9 & 12 & 3.8 \\
\hline Pain Disorder & 2 & 7 & 9 & 2.9 \\
\hline Panic Disorder & 16 & 11 & 27 & 8.6 \\
\hline $\begin{array}{l}\text { Phantom Limb } \\
\text { Phenomenon }\end{array}$ & 1 & 2 & 3 & 1.0 \\
\hline Phobic Disorder & 7 & 5 & 12 & 3.8 \\
\hline Postpartum Psychosis & 0 & 2 & 2 & 0.6 \\
\hline PTSD & 1 & 0 & 1 & 0.3 \\
\hline Rumination Disorder & 1 & 0 & 1 & 0.3 \\
\hline Schizophrenia & 1 & 1 & 2 & 0.6 \\
\hline Sexual Dysfunction & 14 & 0 & 14 & 4.5 \\
\hline Sleep Disorder & 4 & 6 & 10 & 3.2 \\
\hline Social Anxiety Disorder & 7 & 2 & 9 & 2.9 \\
\hline $\begin{array}{c}\text { Somatic Symptom } \\
\text { Disorder } \\
\end{array}$ & 12 & 15 & 27 & 8.6 \\
\hline $\begin{array}{l}\text { Substance Abuse } \\
\text { Disorder }\end{array}$ & 1 & 0 & 1 & 0.3 \\
\hline Total & 162 & 151 & 313 & 100 \\
\hline & Table & & & \\
\hline
\end{tabular}

Referrals received for various reasons. Majority of patients 40 (12.8\%) were having Depressive Disorder, 29 (9.3\%) for Functional Neurological Symptom Disorder, 28 (8.9\%) for Generalised Anxiety disorder, 27 (8.6\%) for Panic Disorder and Somatic Symptom Disorder each. 20 (6.4\%) for Illness Anxiety Disorder, 14 (4.5\%) for Sexual Dysfunction, 13 (4.25\%) for Dissociative Disorders, 12 (3.8\%) for phobic disorders and OCD each. 10 (3.2\%) for Sleep Disorders, 9 (2.9\%) for Pain Disorders and Social Anxiety Disorders each. 7 (2.2\%) for Bipolar Affective Disorder, 6 (1.9\%) for Anxiety Disorders due to another medical condition and Brief Psychotic Disorders each. 5 (1.6\%) for Autism Spectrum Disorder, 4 (1.3\%) for ADHD, for Acute Stress Reaction, for Delusional Disorders, for Eating Disorders each. 3 (1.0\%) for Elimination Disorders, for Intellectual Disability, for Phantom limb phenomenon, for Illness Anxiety Disorder each. 2 (0.6\%) for BPSD, for Chronic Fatigue Syndrome, for post-partum psychosis, for schizophrenia each, 1 (0.3\%) for Conduct Disorder, for Irritable Bowel Syndrome, for Tic Disorder, for PTSD, for Rumination Disorder, for Substance Abuse Disorder each.

\section{DISCUSSION}

The psychopathology in the hospitalised population at any moment, even with conservative estimations, exceeds $30 \%$ and ranges from 30 to 50\%.14-16 Most of these patients have problems which have been the reason that led their physicians to refer them for a psychiatric consultation. ${ }^{17}$

Kisely et al ${ }^{18}$ claimed that $30-60 \%$ of admitted patients in general hospitals suffer from one major psychiatric disorder. Comorbid psychiatric disorders negatively affect the course and prognosis of the medical diseases due to changes and irregularities in autonomous nervous, endocrine and immune systems. The management of comorbid psychiatric and physical illness is an important issue for health services. ${ }^{19-24}$

This study examined the socio-demographic parameters, sources of referrals and diagnostic pattern of psychiatric disorders by assessing the referrals of patients sent for psychiatric consultation. According to this study, the mean age of referred patients was 32.6 years, a finding which is in agreement with other studies. 25 In addition, most of the patients referred for psychiatric consultation were adults, which supports the general view that psychiatric disorders preferentially afflict the young adult population worldwide. It also indicated that the psychiatric services are critical for mental health of socio-economically most productive age group.

Also in agreement with other studies was the finding that less 26,27 male patients (48\%) were referred than females $(52 \%)$. Female population, mostly housewives consisted of majority of the referrals in our study, but other data available on this subject is conflicting. Some studies suggest that referrals are more common in the males 28,29 while others favour females ${ }^{11,30}$, it has been shown that women are more likely to suffer from psychiatric disorders like depression in the wake of a stressful life event. ${ }^{31}$ This could account for the higher inpatient referrals among women.

Similar to our findings, Bourgeois et $\mathrm{al}^{32}$ observed that the group of patients seen was $52 \%$ male, though the mean age was 48.59 years. Contrasting to our findings, approximately $64.8 \%$ of the patients were females, as reported by Alhuthail et $\mathrm{al}^{33}$ and Ozkan et al.34 observed in his study that the 
demographic profile of the referred patients in terms of gender and age has changed over the years.

Majority of the subjects were mainly from rural areas. This finding indicates that the possibility of fact that this institute is situated in a city surrounded by villages.

In our study, almost all the departments sent the referrals, though the most common were from Cardiology, Neurology, General Medicine, Gastroenterology, and Physical Medicine \& Rehabilitation etc. Cardiology sent almost one fourth of the total referrals $(22.7 \%)$. Second in line was department of Neurology (14.7\%).

Similar results were observed in previous studies too. Ozkan ${ }^{35}$ observed in his study that between the years 1989 and 1991, the distributions of consultations made by various referring clinics were, Internal Medicine (48.99\%), Surgery (21.21\%), and Neurology (9.43\%). In the years 1995 and 1996, the distribution was - Internal Medicine (41.8\%), Surgery (31.8\%), Physical Therapy and Rehabilitation (7.6\%). In the years 1997 and 1998, the highest number of consultations were requested by Internal Medicine $(38.8 \%)$. This was followed by Surgery (24.1\%). In 2003, the distribution was - Internal Medicine (50.1\%), Surgery (26.6\%), and Physical Therapy and Rehabilitation (10.0\%).

In most of the previous similar studies. $14,36,37$, the highest proportion of referrals have been from the Department of Internal Medicine.

Forty-five percent of consultations in the study by Alhuthail ${ }^{1}$ were from Medicine followed by Surgery (25.3\%). $77 \%$ of the total sample reviewed by Ku et al ${ }^{38}$ was from the Department of Medicine. Physicians and surgeons are increasingly becoming aware that one third to two thirds of their patients have significant psychiatric symptomatology which is amenable to treatment by psychiatrists. 39,40 The fact, that psychiatric patients can also present to the medical or surgical units due to antecedent physical illnesses and may need additional care by psychiatrists is being recognised. ${ }^{41}$

A large scale study done by Gilli $\mathrm{M}$ et al showed that $56.8 \%$ of patients with chronic somatic disease had some kind of mental disorder particularly those suffering from neurological, oncological or liver disease. ${ }^{42}$ Data shows that in the presence of obvious medical disease psychiatric issues are often over looked.43This may be the reason why in majority of the cases in our study only psychiatric opinion was sought as opposed to being included in the management plan. It is important to realise that in certain common chronic medical diseases like heart and lung disease, diabetes and arthritis, psychiatric comorbidity can contribute to worsening of symptoms as well as prognosis. ${ }^{44}$

In our study, most referrals were for patients with Depression (12.8\%). Apart from this, other common reasons of referral were for Functional Neurological Symptom Disorder, Generalised Anxiety disorder, Panic Disorder and Somatic Symptom Disorder, Illness Anxiety Disorder, Sexual Dysfunction, Dissociative Disorders, etc. Our study was more or less similar to study conducted by Yousafzai, et al ${ }^{45}$ which shows that the most common diagnoses are in order of depression (39.1\%), conversion disorder (13.6\%), and delirium (6.4\%).

Although depression is the most frequent diagnosis in our study, depression is the third- leading diagnosis in the Hansen study. 46 Depression is almost three times more prevalent in our study than in the Hansen study. This may be due to the lower socioeconomic status of the population and poorer facilities available which leads to higher rates of depression. In a study in a tertiary care hospital in North India, the most frequent psychiatric diagnoses were depressive disorder (25\%), anxiety disorder (15\%), and substance-related disorder (13\%), respectively. ${ }^{47}$ The preponderance of mood, physical and somatic, anxiety, and other complaints were nearly keeping with the diagnostic profiles. The relatively greater presentation with mood in this study is similar to a study conducted in Nepal among adult referred-OPD cases. ${ }^{9}$

Like other studies, we also observed to have higher number of referrals for patients with Depression considering the prevalence rate of depression in general population. A good number of referrals were made for further and adequate management of diagnosed cases who were admitted for treatment of other illnesses. It was also deduced that lesser than expected referrals from Neurology could be due to prescription of psychotropic medication by neurologists themselves or doctors have become more skilled at diagnosing and managing patients without referring them to psychiatrist opinion.

Reasons for referral, According to Ozkan ${ }^{35}$ an overall assessment of the patterns of reasons for referral over 14 years revealed that during the first years, consultation requests for differential diagnoses ( organic-psychogenic) (25\%)\} were predominant. Consultation requests for anxiety (14.4\% in 1989-1991; $17.7 \%$ in 2003) and depressive state (14\% in $1989-1991 ; 21.8 \%$ in 2003 ) associated with or accompanying physical illness have meaningfully increased in 14 years. Confusional state $(10.3 \%$ in $1997-1998 ; 11.8 \%$ in 2003) has become the third most-occurring reason for consultation in the last 6 years. Past psychiatric history has always been regarded as a routine reason for psychiatric consultation.

One of the main objectives of the referrals is that psychiatry in medicine is not limited to "functional cases or suicide attempts" and psychiatric disorders of various kinds occur in medical patients (comorbidity). As the psychiatric services became available in general hospitals, not only was there an increase in the number of requests for psychiatric consultation, but also reasons for psychiatric consultations grew in kind such that psychiatric cooperation was indicated for all kinds of psycho-situational conditions (e.g. organic mental, psychosocial, behavioural, adaptive disturbance) associated with or accompanying physical disorders.

Diefenbacher and Strain ${ }^{48}$ reported that the primary reasons for referral remained constant, with "Depression and behavioural management/agitation" being the most frequent. Grant et al ${ }^{49}$ reported that in a study covering a ten-year period, depression and chemical dependency assessment appeared to be the main reasons for referral.

\section{CONCLUSIONS}

Mood, physical and somatic symptoms, anxiety, were common presenting complaints among referrals to psychiatric outpatient. Common diagnoses among these cases were Depression, Affective disorders, Anxiety Disorders, and Somatoform disorders. A great majority had one or other physical comorbidities.

Physical diseases were comorbid with psychiatric disorders, hence stressing the need of closer integration of psychiatric services with other specialties, and more interaction between psychiatrist and physician is needed. 
An organised consultation liaison setup can minimise the economic burden on health delivery system of the state.

Given the rising incidence of psychiatric illness globally and its contribution to prognosis of many medical diseases, steps should be taken to create a proper system/criteria of referral.

\section{Implications}

Inter-departmental collaboration and multidisciplinary approach is necessary for the holistic management of psychiatric problems. To treat comorbid psychiatric disorders is very important because they affect the course and prognosis of the medical diseases.

Studies should be carried out in which effectiveness of psychiatry referrals is assessed at multiple tertiary care institutes.

\section{REFERENCES}

1. Lipowski ZJ. Consultation-liaison psychiatry: an overview. Am J Psychiatry 1974;131(6):623-30.

2. Lipowski ZJ. Linking mental and medical health care: an unfinished task. Psychosomatics 1988;29(3):249-53.

3. Schwab JJ. Consultation-liaison psychiatry: a historical overview. Psychosomatics 1989;30(3):245-54.

4. Becker AE, Kleinman A. Mental health and the global agenda. N Engl J Med 2013;369(1):66-73.

5. Javed A, Ashfaq A, Saeed F. Psychiatric referrals in multidisciplinary hospital. JPMI 2004;18(4):626-30.

6. Sharpe M, Hawton K, Seagroatt V, et al. Depressive disorders in long term survivors of stroke. Association with demographic and social factors, functional status, and brain lesion volume. $\mathrm{Br} \mathrm{J}$ Psychiatry 1994;164(3):380-6.

7. De AK, Kar P. Psychiatric disorders in medical inpatientsa study in teaching hospital. Ind J Psychiatry 1998;40(1):73-8.

8. Fryne A, Buckley P, Larkin C, et al. Consultation-liaison psychiatry within the general hospital: referral pattern and management. Irish Med J 1992;85(3):112-4.

9. Shakya DR, Pandey AK, Shyangwa PM, et al. Psychiatric morbidity profiles of referred psychiatry OPD patients in a general hospital. Indian Medical Journal 2009; 103(12):407- 11.

10. Silverstone PH. Prevalence of psychiatric disorders in medical inpatients. J Nerv Ment Dis 1996;184(1):43-51.

11. Saravay SM, Lavin M. Psychiatric comorbidity and length of stay in the general hospital. A critical review of outcome studies. Psychosomatics 1994;35(3):233-52.

12. Katon WJ. Epidemiology and treatment of depression in patients with chronic medical illness. Dialogues Clin Neurosci 2011;13(1):7-23.

13. Sheehan D, Lecruebier Y, Janavs J, et al. The miniinternational neuropsychiatric interview M.I.N.I: the development and validation of a structured diagnostic psychiatric interview for DSM-IV and ICD-10. J Clin Psychiatry 1998;59(Suppl 20):22-33, quiz 34-57.

14. Greenhill MH. Psychiatric units in general hospitals: 1979. Hosp Community Psychiatry 1979;30(3):169-82.

15. Lipowski ZJ, Wolston EJ. Liaison psychiatry: referral patterns, and their stability over time. Am J Psychiatry 1981;138(12):1608-11.
16. Schulberg HC, Burns BJ. The nature and effectiveness of general hospital psychiatric services. Gen Hosp Psychiatry 1985;7(3):249-57.

17. Christodoulou C, Fineti K, Douzenis A, et al. Transfers to psychiatry through the consultation-liaison psychiatry service: 11 years of experience. Annals of General Psychiatry 2008;7:10.

18. Kisely S, Horton-Hausknecht J, Miller K, et al. Increased collaboration between primary care and psychiatric services. A survey of general practitioners' views and referrals. Aust Fam Physician 2002;31(6):587-9.

19. Chadda RK. Psychiatry in non-psychiatric setting-a comparative study of physicians and surgeons. J Indian Med Assoc 2001;99(1):24, 26-27, 62.

20. Holmes J, Bentley K, Cameron I. A UK survey of psychiatric services for older people in general hospitals. Int J Geriatr Psychiatry 2003;18(8):716-21.

21. Lipsitt DR. What do consultation-liaison (C-L) psychiatry and psychosomatic medicine (PM) have in common? Seishin Shinkeigaku Zasshi 2003;105(3):332-8.

22. Maroufi M, Pedram A, Malekian A, et al. Consultationliaison psychiatry in a general hospital. JRMS 2006; 11(3):193-7.

23. Ozaki N. Present status of consultation-liaison psychiatry. Seishin Shinkeigaku Zasshi 2003;105(12): 1431-6.

24. Sternhell PS, Corr MJ. Psychiatric morbidity and adherence to antiretroviral medication in patients with HIV/AIDS. Aust N Z J Psychiatry 2002;36(4):528-33.

25. Creed F, Guthrie E, Black D, et al. Psychiatric referrals within the general hospitals: comparison with referrals to general practitioners. Br J Psychiatry 1993;162: 204-11.

26. Strathdee G, King MB, Araya R, et al. A standardized assessment of patients referred to primary care and hospital psychiatric clinics. Psychol Med 1990;20(1): 219-24.

27. Dhavale HS, Barve RG. Psychiatric referral pattern in general hospital. J Postgrad Med 1990;36(4):199-202.

28. Bhogale GS, Katte RM, Heble SP, et al. Psychiatric referrals in multispecialty hospital. Indian J Psychiatry 2000;42(2):188-94.

29. Chen CY, Yeh SS. The present status of psychiatric consultation in Chang Gung Memorial Hospital, Keelung: a report of clinical characteristics. Changgeng Yi Xue Za Zhi 1996;19(4):331-6.

30. Aghanwa H. Consultation liaison psychiatry in Fiji. Pacific Health Diag 2002;9(1):21-8.

31. Keita GP. Psychosocial and cultural contributions to depression in women: considerations for women midlife and beyond. J Manag Care Pharm 2007;13(9 Suppl A):S12-5.

32. Bourgeois JA, Wegelin JA, Servis ME, et al. Psychiatric diagnoses of 901 inpatients seen by consultation-liaison psychiatrists at an academic medical center in a managed care environment. Psychosomatics 2005; 46(1):47-57.

33. Alhuthail YR. Timing of referral to consultation-liaison psychiatry. International Journal of Health Sciences (Qassim) 2009;3(2):170-5. 
34. Ozkan M. An evaluation of the development of consultation liaison psychiatry in the Istanbul faculty of medicine: psychiatric consultations in 14 years. J Ist Faculty Med 2005;68(4):105-12.

35. Ozkan $S$, Yücel B, Turgay $M$, et al. The development of psychiatric medicine at Istanbul faculty of medicine and evaluation of 889 psychiatric referrals. Gen Hosp Psychiatry 1995;17(3):216-23.

36. Perez EL, Silverman M. Utilisation pattern of a Canadian psychiatric consultation service. Gen Hosp Psychiatry 1983;5:185-90.

37. Zuo C, Yang L, Chu CC. Patterns of psychiatric consultations in a Chinese general hospital. Am J Psychiatry 1985;142(9):1092-4.

38. $\mathrm{Ku} \mathrm{KH}$, Nguyen GHD, Ng YK. Consultation liaison psychiatry in kwai chung hospital. Hong Kong Journal of Psychiatry 1997;7(1):3-8.

39. Nabarro J. Unrecognised psychiatric illness in medical patients. Br Med J (Clin Res Med)1984;289(6446):635-6.

40. Von-Ammon Cavanaugh S. The prevalence of emotional and cognitive dysfunction in a general medical population using the MMSC, GHQ and BDI. Gen Hosp Psychiatry 1983;5(1):15-24.

41. Munjal GC, Ahuja N. Consultation liaison psychiatry. In: Vyas JN, Ahuja N, eds. Textbook of postgraduate psychiatry. 2nd edn. New Delhi: Jaypee Brothers Medical Publishers (P) Ltd 1999:423-31.

42. Gili M, Comas A, García-García M, et al. Comorbidity between common mental disorders and chronic somatic diseases in primary care patients. Gen Hosp Psychiatry 2010;32(3):240-5.
43. Clarke DM, Minas IH, McKenzie DP. Illness behaviour as a determinant of referral to a psychiatric consultation /liaison service. Aust N Z J Psychiatry 1991;25(3):330-7.

44. Kapfhammer HP. The relationship between depression, anxiety and heart disease-a psychosomatic challenge. Psychiatr Danub 2011;23(4):412-24.

45. Yousafzai AW, Jehangiri AR, Kazim M, et al. Demographic and clinical characteristics of patients referred to psychiatric unit in a tertiary care hospital. J Ayub Med Coll Abbottabad 2015;27(1):208-11.

46. Hansen MS, Fink P, Frydenberg M, et al. Mental disorders among internal medical inpatients: prevalence, detection, and treatment status. J Psychosom Res 2001;50(4):199-204.

47. Jhanjee A, Kumar P, Srivastava S, et al. A descriptive study of referral pattern in department of psychiatry of a tertiary care hospital of north India. Medicine (Baltimore) 674:46-0.

48. Diefenbacher A, Strain JJ. Consultation liaison psychiatry: stability and change over a 10-year-period. General Hosp Psychiatry 2002;24(4):249-56.

49. Grant JE, Meller W, Urevig B. Changes in psychiatric consultations over ten years. Gen Hosp Psychiatry 2001; 23(5):261-5. 